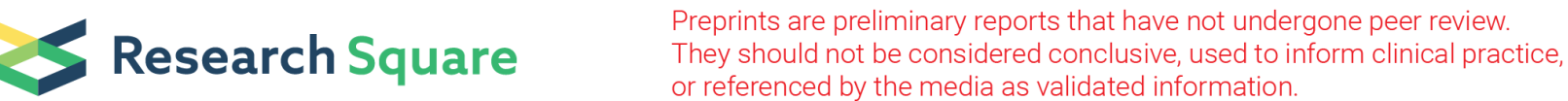

\section{Significance of nuclear upregulation of LOXL2 in fibroblasts and myofibroblasts in the fibrotic process of acute respiratory distress syndrome}

\author{
Ayako Matsuo \\ University of Miyazaki \\ University of Miyazaki \\ Hironobu Tsubouchi \\ University of Miyazaki \\ Ayako Miura \\ University of Miyazaki \\ Takafumi Shigekusa \\ University of Miyazaki \\ Nobuhiro Matsumoto \\ University of Miyazaki \\ Masamitsu Nakazato \\ University of Miyazaki
}

Shigehisa Yanagi ( $\nabla$ yanagi@med.miyazaki-u.ac.jp )

\section{Research}

Keywords: lysyl oxidase-like 2, nuclear upregulation, myofibroblast, fibroblast-to-myofibroblast transition, Snail, acute respiratory distress syndrome, lung scarring

Posted Date: February 24th, 2020

DOI: https://doi.org/10.21203/rs.2.24386/v1

License: (c) (1) This work is licensed under a Creative Commons Attribution 4.0 International License. Read Full License 


\section{Abstract}

Background: Fibrotic scarring is an important prognostic factor for acute respiratory distress syndrome (ARDS). Lysyl oxidase-like 2 (LOXL2), an amine oxidase, is thought to make an integral contribution to fibrotic scarring by facilitating collagen cross-linking. LOXL2 has also been proposed to epigenetically regulate gene expression to direct cell fate. Recent clinical outcomes demonstrated the ineffectiveness of an inhibitory monoclonal antibody against LOXL2 in patients with organ fibrosis, including fibrosis of the lungs, suggesting that sole targeting of the extracellular activity of LOXL2 is insufficient to prevent fibrotic scarring. Moreover, the involvement of LOXL2 in human ARDS remains unknown.

Methods: Expression dynamics of LOXL2 during the pathological process of bleomycin (BLM)-induced lung injury model were measured by qRT-PCR and western blotting. The principal cell types expressing LOXL2 and its cellular localization were determined by immunohistochemistry and confocal microscopy. Mlg 2908, a murine lung fibroblast line, was transfected with LOXL2 siRNA or control siRNA, and then assessed for transforming growth factor (TGF)- $\beta 1$-induced Axin2+ myofibrogenic progenitor (AMP) marker expression, actin filament expression, myofibroblast differentiation, collagen expression, and alteration of the TGF- $\beta 1 / \mathrm{Smad} / \mathrm{Snail}$ pathway by phalloidin staining, qRT-PCR, western blotting, and immunocytochemistry. Levels of LOXL2 in bronchoalveolar lavage fluid (BALF) in patients with ARDS and control subjects were measured by enzyme-linked immunosorbent assay.

Results: LOXL2 expression was elevated in lung tissue in the fibrotic phase after injury. Nuclear upregulation of LOXL2 in fibroblasts and myofibroblasts, as well as nuclear upregulation of Snail in myofibroblasts, was evident in fibrotic lung tissue after injury. LOXL2 knockdown blocked TGF- $\beta 1$-induced AMP marker expression, appearance of proto-myofibroblasts, evolution of differentiated myofibroblasts, collagen expression, and pSmad2/Snail induction in lung fibroblasts. We detected high levels of LOXL2 protein in the BALF from patients with ARDS, specifically during the fibrotic phase.

Conclusions: Our results revealed that nuclear LOXL2 is upregulated in lung fibroblasts and myofibroblasts after injury and is required for generation of myofibroblast and maintenance of AMP. The high levels of LOXL2 in human ARDS lung suggest that inhibition of both intracellular and extracellular LOXL2 activity represents an attractive therapeutic target for ARDS and lung scarring.

\section{Background}

Acute respiratory distress syndrome (ARDS) is a common acute critical illness and therefore a major public health problem: among intensive care units (ICUs) in 50 countries, ARDS constitutes $10.4 \%$ of total ICU admissions [1]. Despite substantial advances in both critical care and mechanistic understanding of ARDS, the prognosis of this life-threating syndrome remains poor, with a mortality rate of $40 \%[1,2]$. The pathological changes associated with ARDS include dysregulated proinflammatory cytokine release and leukocyte recruitment arising from multiple etiologies, disruptions of alveolar epithelial and endothelial 
barriers, influx of protein-rich edema within the interstitium and alveolus, and eventual irreversible fibrotic scarring of lung parenchyma [2-4].

Among the pathological manifestations in ARDS, fibrotic scarring of lung parenchyma is increasingly recognized as an important prognostic factor. Alveolar fibrosis is correlated with increased mortality in ARDS [5]. Furthermore, lung parenchymal fibroproliferation (e.g., traction bronchiolectasis or bronchiectasis), assessed by chest high-resolution computed tomography in patients with early ARDS, predicts increased mortality and ventilator dependency [6]. Thus, in addition to reduction of early inflammation, prevention of aberrant fibroproliferation and scarring are considered to be key strategies for resolving ARDS. Two anti-fibrotic drugs are already available for treatment of idiopathic pulmonary fibrosis (IPF), but they offer only modest clinical benefits [7, 8]. Moreover, no pharmacologic therapies, including anti-fibrotic agents, have yet been approved for ARDS.

In normal wound healing, expansion of resident fibroblasts and provisional matrix formation resolve transiently following reconstitution of alveolar epithelial integrity, and these sequential events lead to restoration of normal lung function. By contrast, when wound healing goes awry, extensive and prolonged activation of fibroblasts occurs, leading to excessive dense extracellular matrix (ECM) deposition in alveolar parenchyma, culminating in persistent respiratory failure. Myofibroblasts, defined by the expression of a-smooth muscle actin (a-SMA), are essential effector cells for the propagation of fibrotic ARDS and other fibrotic diseases $[9,10]$. High cellular activities of myofibroblasts (production of insoluble ECM and cellular contraction) trigger creation of a pathologic microenvironment, destruction of normal tissue architecture, and physical organ deformity [9]. Furthermore, myofibroblasts perturb alveolar epithelial repair by releasing inflammatory mediators that induce alveolar epithelial apoptosis [11]. Resident mesenchymal cells are recognized as the major origin of myofibroblasts in lung fibrosis [12]. A single-cell RNA sequencing and signaling lineage reporter approach demonstrated that myofibroblasts in the lung preferentially emerge from Axin2 + myofibrogenic progenitor (AMP) cells, lineage within the resident mesenchymal population [13]. Myofibroblast generation begins with the appearance of protomyofibroblasts, whose stress fibers contain only $\beta$ - and $y$-cytoplasmic actins $[14,15]$. Protomyofibroblasts evolve into differentiated myofibroblasts, which have greater contractile force than protomyofibroblasts. Myofibroblast differentiation occurs in response to multiple pro-fibrotic mediators including transforming growth factor $\beta 1$ (TGF- $\beta 1$ ), a master regulator of myofibroblast differentiation in virtually all types of fibrosis $[4,9,16]$, as well as external mechanical cues arising from stiff fibrotic ECM created by the myofibroblasts themselves [17]. Agents targeting prevention of excessive myofibroblast generation and blocking TGF- $\beta 1$ signaling, with the ultimate goal of ameliorating fibrotic scarring, represent a promising strategy for the development of therapeutics for ARDS patients.

Lysyl oxidase (LOX) and the related enzyme, LOX-like 2 (LOXL2), are copper-dependent amine oxidases, that catalyze the oxidative deamination of $\varepsilon$-amines of lysine and hydroxylysine residues within collagen and elastin [18-20]. This reaction generates highly reactive aldehydes (allysine) that condense with other allysines or lysines, facilitating the formation of inter- and intramolecular cross-links that modify ECM network [18-20]. These molecules have been implicated in the pathogenesis of cancer and organ fibrosis 
[21-23]. LOXL2 expression is elevated in the stroma of human tumors, IPF, and liver fibrosis [21, 24]. In addition, higher serum LOXL2 levels are associated with disease progression of IPF [25]. An inhibitory monoclonal antibody against LOXL2 (AB0023) ameliorates bleomycin (BLM)-induced lung fibrosis, decreasing both the level of cross-linking in fibrillary collagen and the number of myofibroblasts [21]. However, recent phase 2 trials revealed that treatment with simtuzumab, a humanized variant of AB0023, did not confer a clinical benefit in patients with IPF or fibrotic disorders in other organs [26-28]. These results raise the possibility that sole targeting of the extracellular enzymic activity of LOXL2 is insufficient for prevention of deleterious fibrotic response to injury.

In addition to their extracellular activities, LOX and LOXL2 play crucial intracellular roles in the regulation of chromatin structure and gene transcription [29-33]. Recent studies demonstrated that silencing LOXL2 decreases a-SMA expression and cell proliferation in lung fibroblasts [24,34]. The sequential differentiation events of fibroblasts are as follows: initiation from AMPs, differentiation into protomyofibroblasts, and transition into differentiated myofibroblasts. The role of LOXL2 in these events, as well as its cellular localization during the progression of fibrosis, remains unknown. In addition, it is not clear whether LOX or LOXL2 is more important in the progression of lung scarring. Moreover, we have no information about the involvement of LOXL2 in the pathogenesis of human ARDS.

In this study, we examined the expression dynamics of LOX and LOXL2, as well as cellular localization of LOXL2, during the pathologic process of BLM-induced lung injury. We then investigated the role of LOXL2 in fibroblast-proto-myofibroblast-differentiated myofibroblast differentiation, AMP population, and myofibroblast activity. Finally, we determined the LOXL2 levels in bronchoalveolar lavage fluid (BALF) from patients with various pathological stages of ARDS.

\section{Methods}

BLM-induced lung injury in mice

Eight-week-old male C57BL/6J mice were purchased from Charles River Japan (Yokohama, Japan). Mice were anesthetized by an intraperitoneal injection of medetomidine hydrochloride $(0.3 \mathrm{mg} / \mathrm{kg})$, midazolam ( $4 \mathrm{mg} / \mathrm{kg}$ ), and butorphanol tartrate $(5 \mathrm{mg} / \mathrm{kg}$ ), and then intratracheally injected with $6 \mathrm{U} / \mathrm{kg} \mathrm{BLM}$ sulfate (Sigma-Aldrich, St. Louis, MO). Lungs were harvested on day 7 or 14 after BLM instillation. All animal experiments were performed in accordance with the Japanese Physiological Society's guidelines for animal care and were approved by the University of Miyazaki Ethics Committee on Animal Experimentation.

Cell Cultures, Cell Transfection, And TGF- $\beta 1$ Treatment

Mlg $2908\left(C C L-206^{T M}\right)$, a murine lung fibroblast cell line, was purchased from American Type Culture Collection (Manassas, VA). The cells were maintained in Dulbecco's Modified Eagle's Medium/F12 (Sigma-Aldrich) containing 10\% heat-inactivated fetal bovine serum (Biowest, Nuaillé, France) and 1\% penicillin/streptomycin. Cultured Mlg 2908 were grown in $5 \% \mathrm{CO}_{2}$ humidified atmosphere at $37^{\circ} \mathrm{C}$. 
Passage was performed every 3 days. For LOXL2 knockdown experiments, the cells were seeded onto 6well cell culture plates $\left(2.0 \times 10^{5} /\right.$ well, Thermo Fisher Scientific, Waltham, MA) or Lab-Tek II chamber slides (0.4 × 105/well, Sigma-Aldrich). LOXL2 small interfering RNA (siRNA; $10 \mathrm{nM}$ ) was transfected into Mlg 2908 using Lipofectamine RNAiMAX Reagent (Thermo Fisher Scientific) 72 hours after seeding. The LOXL2 siRNA target sequences were as follows: first, 5'-GAACAGAAGUUCGAACACUTT-3'; second, 5'GGAGUGAAGUGCUCAGGAATT-3' (Life Technologies Japan, Tokyo, Japan). A scrambled siRNA was used as a control. At 72 hours after siRNA treatment, human recombinant TGF- $\beta 1$ ( $5 \mathrm{ng} / \mathrm{ml}$; R\&D, Minneapolis, $\mathrm{MN}$ ) or dimethyl sulfoxide (DMSO, control) was added to the medium. The cells were harvested for quantitative real-time PCR (qRT-PCR) and western blotting 24 hours after TGF- $\beta 1$ treatment.

Immunostaining and actin filament staining of cells on chamber slides were also performed 24 hours after TGF- $\beta 1$ treatment, as described below.

Western Blotting

Whole lung tissues and cultured Mlg 2908 were homogenized and centrifuged at $10,000 \times \mathrm{g}$ to remove cell debris. Protein content of lysates was measured by Bradford protein assay. Equal amount of proteins was fractionated by $10 \%$ SDS-PAGE, and transferred to Immobilon-P transfer membrane (Merck Millipore, Burlington, MA). Expression levels of each molecule were analyzed by western blotting using antibodies recognizing the following proteins: LOX (Santa Cruz Biotechnology, Dallas, TX), LOXL2, Snail (Abcam, Cambridge, MA), pSmad2, Smad2 (Cell Signaling Technology, Danvers, MA), and $\beta$-actin (Sigma-Aldrich). Protein expression was quantified by densitometry using the Fusion FX software (Vilber Lourmat, Collégien, France).

qRT-PCR

Total RNA was extracted from lungs and Mlg 2908 cells using the Trizol reagent (Invitrogen, Carlsbad, CA). First-strand complementary DNA was synthesized using high-capacity cDNA reverse transcription kits (Applied Biosystems, Foster City, CA). qRT-PCR was performed with the following TaqMan/Applied Biosciences primers (Thermo Fisher Scientific): Lox (Mm00495386_m1), Loxl2 (Mm00804740_m1), Col1a1 (Mm00801660_g1), and Postn (Mm01284919_m1). The transcription levels of target genes were standardized against those of the Hprt1 (Mm03024075_m1) gene and calculated by the $\Delta \Delta \mathrm{Ct}$ method.

Histology, Immunostaining, And Confocal Microscopy

Lungs were removed, fixed in $4 \%$ buffered formalin, and embedded in paraffin. Lung sections $(4 \mu \mathrm{m})$ were mounted on slides for staining with hematoxylin-eosin and Masson's trichrome (American Master Tech Scientific, Lodi, CA). For immunostaining, lung sections were permeabilized with $0.1 \%$ Triton X-100 in PBS (PBS-T) for 30 minutes, and then pre-treated with $3 \%$ hydrogen peroxide to remove endogenous peroxidase. For immunostaining to detect surfactant protein $\mathrm{C}$ (SP-C), antigen activation was performed by heating the sections in an autoclave for 20 minutes at $105^{\circ} \mathrm{C}$ in a HistoVT One (Nacalai Tesque, Kyoto, Japan), followed by cooling at room temperature. All sections were blocked with $2.5 \%$ goat serum / 2.5\% donkey serum and $0.1 \%$ bovine serum antigen (BSA) in PBS-T for 60 minutes at room temperature. 
Each section was incubated overnight at $4{ }^{\circ} \mathrm{C}$ with primary antibodies against the following proteins: LOXL2 (1:400; Abcam, Cambridge, MA), Podoplanin (1:100; MBL, Nagoya, Japan), SP-C (1:200; SigmaAldrich), CD11b (1:200; Cell Signaling Technology), fibroblast surface protein (FSP, 1:800; Cell Signaling Technology), Snail (1:1,000; Abcam), and a-SMA (1:400; Sigma-Aldrich). After washing with PBS, the following secondary antibodies were used: Alexa Fluor 488 anti-rabbit lgG, Alexa Fluor 594 anti-rabbit IgG, Alexa Fluor 594 anti-goat IgG (Thermo Fisher Scientific). Nuclei were counterstained with 4',6diamidino-2-phenylindole (DAPI; Dojindo, Kumamoto, Japan). Images of immunofluorescence staining of cells and tissues were acquired using a Nikon $\mathrm{C} 2$ + confocal laser scanning microscope (Nikon, Tokyo, Japan). For quantification of co-localized cells from double-immunostained slides, one investigator took photos of 10 random fields at 200-fold magnification in a blinded fashion (i.e., without knowledge of the experimental or control groups from which the sections were taken), and the cells in each field were counted independently by two other investigators in a blinded fashion.

Immunocytochemistry And Actin Filament Staining

Individual siRNA-transfected and TGF- $\beta 1$-treated Mlg 2908 cells grown on chamber slides were rinsed in PBS, fixed with $4 \%$ buffered formalin for 20 minutes, and blocked in $5 \%$ donkey serum and $0.1 \%$ BSA in PBS-T for 30 minutes at room temperature. Immunostaining on chamber slides with anti-a-SMA antibody (1:400; Sigma-Aldrich) was performed overnight at $4{ }^{\circ} \mathrm{C}$. Nuclei were counterstained with DAPI. The a-SMA-positive and DAPI-positive cells were counted in 10 random fields per chamber at 200-fold magnification. The percentages of a-SMA-positive cells were calculated by dividing the number of aSMA-positive cells by the number of DAPI-positive cells. For actin filament staining, cells were stained with Acti-stain 488 phalloidin (1:150; Cytoskeleton, Denver, CO).

Quantification Of Intracellular Actin Filament

Intracellular actin filaments were quantified as follows. Twenty equally distributed horizontal lines were overlaid on the actin-stained images. For each line, the number of the intersection points with actin filaments was manually counted. Intracellular actin filaments were quantified in 50 cells in each sample. The index of intracellular actin filaments was defined as the number of intersections per cell.

\section{Human BALF Preparation}

We retrospectively collected clinical data and BALF samples of patients with ARDS or pulmonary sarcoidosis (as disease control) admitted to the University of Miyazaki Hospital between 2009 and 2015. Subjects included 33 patients with ARDS (20 males and 13 females; mean age 67.6 [28-90] years), and 7 patients with pulmonary sarcoidosis ( 2 males and 5 females; mean age 58.6 [34-73] years). Patients with cancer in any organ were excluded from the study. The study protocol was approved by the University of Miyazaki Research Ethics Committee (0-0531). Informed consent was obtained in the form of opt-out on our hospital website. BALF samples were obtained from individual patients when they underwent diagnostic bronchoalveolar lavage. BALF was centrifuged at 1,000 rpm for 5 minutes, and supernatants were stored at $-80^{\circ} \mathrm{C}$ prior to use. 
Enzyme-linked Immunosorbent Assay (ELISA)

LOXL2 concentration in BALF was measured using the human LOXL2 ELISA kit (Abcam).

Statistical analysis

Data are expressed as means \pm SEM. Statistical analyses were performed using GraphPad PRISM 7 (GraphPad Software, La Jolla, CA). Data were analyzed by one-way analysis of variance (ANOVA) followed by Dunnett's multiple comparison test. The Mann-Whitney $U$ test was used for single-parameter comparisons. $\mathrm{P}<0.05$ was considered statistically significant.

\section{Results}

Elevated LOXL2 levels in lungs at the fibrotic phase in BLM-injected mice

To determine whether LOX or LOXL2 is more important to the fibrotic process, we first assessed the expression dynamics of these molecules during the pathological sequence of BLM-induced lung injury. Histological analysis of lungs 7 days after BLM treatment revealed intra-alveolar edema and inflammatory cell infiltration, corresponding to inflammatory phase [35], and those of day 14 showed fibrotic scarring of lung parenchyma with dense collagen deposition, corresponding to the fibrotic phase (Fig. 1a). LOX expression was increased on day 7, but decreased on day 14 at both mRNA and protein levels (Fig. 1, b and c). By contrast, LOXL2 mRNA and protein levels were highest on day 14 (Fig. 1, b and c), suggesting that LOXL2, rather than LOX, plays a more pivotal role in the fibrotic process after lung injury.

Nuclear upregulation of LOXL2 in fibroblasts and myofibroblasts during the fibrotic phase of BLMinduced lung injury

Because we detected the highest LOXL2 expression, as well as a reduction of LOX expression, during the fibrotic phase of lung injury, we focused our subsequent analysis solely on the role of LOXL2 in the pathogenesis of lung fibrosis. Next, we sought to determine the cell type(s) responsible for LOXL2 expression after lung injury. On days 7 and 14, immunopositivity for LOXL2 was primarily localized in the nucleus of fibroblasts and myofibroblasts (Fig. 2, a and b). Together, LOXL2-positive fibroblasts and myofibroblasts totaled $65.8 \%$ and $72.6 \%$ of all LOXL2-positive cells on days 7 and 14 , respectively. These data suggest that nuclear LOXL2 in fibroblasts and myofibroblasts plays an important role in the progression of lung fibrosis.

LOXL2 knockdown inhibits TGF- $\beta 1$-induced fibroblast-to-myofibroblast transition (FMT), AMP marker expression, and collagen expression in lung fibroblasts

As mentioned earlier, we detected strong, nuclear expression of LOXL2 in both fibroblasts and myofibroblasts in the fibrotic phase of BLM-induced lung injury. This led us to hypothesize that LOXL2 contributes to the pathogenesis of lung fibrosis by regulating the FMT. To test this hypothesis, we 
assessed the effect of LOXL2 silencing on the TGF- $\beta 1$-induced FMT in vitro. We transfected Mlg 2908 cells, a murine lung fibroblast cell line, with LOXL2-specific siRNA or control siRNA. We observed approximately $90 \%$ and $40 \%$ reduction of LOXL2 expressions 48 hours after transfection of Mlg 2908 cells with LOXL2 siRNA 1 and LOXL2 siRNA 2, respectively (Fig. 3a). LOXL2 knockdown nearly abolished expression of a-SMA stress fibers in TGF- $\beta 1$-treated Mlg 2908 cells (Fig. 3, b and c). TGF- $\beta 1$-induced Col1a1 expression was attenuated by LOXL2 knockdown (Fig. 3d). In regard to the appearance of protomyofibroblasts, the formation of actin filaments which consist of only $\beta$ - and $y$-actins, a hallmark of proto-myofibroblasts [15], was also abrogated in LOXL2 siRNA-treated Mlg 2908 cells after TGF- $\beta 1$ treatment (Fig. 3, e-g). Furthermore, the expression level of Postn, an intrinsic signaling ligand preferentially expressed in AMPs [13], was also suppressed in LOXL2 siRNA-transfected, TGF- $\beta 1$-treated cells (Fig. 3h). Taken together, these data suggest that LOXL2 commits to fibrogenesis after lung injury by facilitating FMT, maintaining the AMP population, and promoting the secretory activities of myofibroblasts.

LOXL2 Knockdown Inhibits The TGF- $\beta 1 /$ Smad/Snail Pathway In Lung Fibroblasts

We next examined the effect of LOXL2 ablation on TGF- $\beta 1$ signaling pathway. Expression of pSmad2 was suppressed in LOXL2 siRNA-transfected, TGF- $\beta 1$-treated Mlg 2908 cells (Fig. 4, a and b). LOXL2 knockdown inhibited Snail expression in TGF- $\beta 1$-treated Mlg 2908 cells (Fig. 4, a and b). In vivo, we observed strong nuclear expression of Snail in lung myofibroblast in the fibrotic stage of BLM-induced lung injury (Fig. 5 , $a$ and $b$ ). These data suggest that LOXL2 promotes generation of myofibroblasts by upregulating the TGF- $\beta 1 /$ Smad/Snail pathway.

High levels of LOXL2 in BALF from patients with ARDS during the fibrotic phase

To assess the clinical significance of LOXL2 expression in human ARDS, we measured the levels of LOXL2 protein in BALF from patients with ARDS. LOXL2 levels in BALF were higher in patients with ARDS than in counterpart control individuals $(270.0 \pm 157.6 \mathrm{vs}$. $99.0 \pm 26.5 \mathrm{pg} / \mathrm{ml}, \mathrm{P}=0.008$, Fig. 6a). To examine the potential of LOXL2 level as a prognostic predictor of ARDS, we compared the LOXL2 levels in BALF between ARDS patients who had survived and those who had died. Although we did not detect a statistically significant difference, the LOXL2 level was higher in patients who died of ARDS than in their surviving counterparts ( $306.5 \pm 157.0$ vs. $246.2 \pm 153.4 \mathrm{pg} / \mathrm{ml}, \mathrm{P}=0.86$, Fig. $6 \mathrm{~b}$ ). Finally, we assessed LOXL2 levels in BALF from patients with ARDS at various stages of diffuse alveolar damage (DAD), a histological hallmark of ARDS $[3,4]$. Based on the histological findings, DAD phases are divided into three phases, as follows: ( 1 ) exudative phase ( $<72$ hours), characterized by alveolar edema, hyaline membrane formation, and interstitial recruitment of inflammatory cells; (2) proliferative phase (days 4-9), characterized by proliferation of fibroblasts and myofibroblasts accompanied by loose organizing fibrosis; and (3) fibrotic phase (> 10 days), characterized by the formation of scar tissue associated with distorted parenchymal architecture [4, 36, 37]. LOXL2 levels in BALF from patients in the exudative phase of ARDS were comparable with those of counterpart control subjects (Fig. 6c). By contrast, the levels of LOXL2 in BALF from patients in the proliferative or fibrotic phase of ARDS were higher than in those in the 
exudative phase of ARDS or control subjects (control, $99.0 \pm 26.5 \mathrm{pg} / \mathrm{ml}$; exudative phase, $159.1 \pm$ $36.9 \mathrm{pg} / \mathrm{ml}$; proliferative phase, $245.2 \pm 85.5 \mathrm{pg} / \mathrm{ml}$; fibrotic phase, $378.6 \pm 220.3 \mathrm{pg} / \mathrm{ml}$; control vs. proliferative phase, $P=0.0003$; control vs. fibrotic phase, $P=0.007$; exudative phase vs. proliferative phase, $P=0.03$; exudative phase vs. proliferative phase, $P=0.04$; Fig. $6 \mathrm{c}$ ). These results suggest that LOXL2 contributes to the progression of lung fibrosis after acute injury, even in clinical settings.

\section{Discussion}

Identification of a key molecule that drives the fibrotic process of ARDS would contribute greatly to the establishment of a highly effective therapeutic agent against this intractable disorder. Here, we report for the first time the robust, nuclear expression of LOXL2 in fibroblasts and myofibroblasts during the fibrotic phase after injury. siRNA knockdown of LOXL2 in lung fibroblasts led to abrogation of TGF- $\beta 1$-induced AMP marker expression, appearance of proto-myofibroblasts, evolution of differentiated myofibroblasts, and collagen production. LOXL2 silencing in lung fibroblasts blocked the TGF- $\beta 1 /$ Smad/Snail pathway. Nuclear upregulation of Snail was evident in myofibroblasts during the fibrotic phase after lung injury. We detected high levels of LOXL2 protein in the lungs in patients with ARDS, specifically during the fibrotic phase. Excessive propagation of myofibroblasts in patients with ARDS is a serious problem that cannot be overlooked because these cells play important roles in the development of lung scarring. The most essential issue for prevention of fibrotic scarring, and subsequent prolonged respiratory failure, in patients with ARDS is blocking the overproduction of myofibroblasts, a goal for which no therapeutic options currently exist. Our results suggest that inhibition of the activity of nuclear LOXL2 represents an attractive therapeutic target for treating ARDS and preventing lung scarring.

Controlling extracellular LOXL2 activity is important for decreasing microenvironmental mechanical tension and ECM stiffening in fibrotic alveoli. A recent study demonstrated that elevated mechanical tension in alveoli activates a TGF- $\beta 1$ signaling loop in alveolar type 2 cells, which drives periphery-tocenter progression of lung fibrosis [38]. Barry-Hamilton and colleagues [21] reported that treatment with LOXL2 inhibitory monoclonal antibody (AB0023) decreased lung fibrosis and the number of activated fibroblasts in murine lungs. Elevated LOXL2 expression in disease-associated stroma and alveolar epithelial cells was also reported in patients with IPF [21, 24]. However, despite positive preclinical data, a humanized monoclonal antibody against LOXL2, simtuzumab, failed to show benefit over placebo in phase 2 trials in patients with IPF, liver fibrosis, or primary sclerosing cholangitis [26-28]. These clinical results may be due to the inability of the monoclonal antibody to reach the intracellular space, raising the possibility that solely inhibiting the extracellular activity of LOXL2 is insufficient to control fibrotic disease progression. In fact, AB0023 had no direct effects on collagen production or TGF- $\beta$ signaling in vitro [21]. Our results revealed intense nuclear expression of LOXL2 in fibroblasts and myofibroblasts in the lungs after injury. We also demonstrated that siRNA-mediated silencing of LOXL2 effectively blocked TGF- $\beta 1$ induced FMT in lung fibroblasts. In light of our results, we believe that development of drugs with an inhibitory effect on both extracellular and intracellular LOXL2 activities is key for establishing a therapeutic strategy against ARDS and other fibrotic diseases. Recently, potent, irreversible, and highly selective small-molecule inhibitors of LOXL2 have been identified [20]. These inhibitors are thought to be 
capable of cell and nuclear penetration, and could inhibit both intracellular and extracellular LOXL2 activity. Thus, small molecule cell-permeable inhibitors targeting LOXL2 may have great therapeutic value against ARDS. Future work should evaluate the efficacy of small-molecule inhibitors of LOXL2 in ARDS models in order to establish a novel therapeutic strategy in patients with ARDS.

Using double immunostaining and confocal microscopy, we found that fibroblasts and myofibroblasts are the principal cells that express LOXL2 protein after lung injury. We also showed that silencing of LOXL2 expression in lung fibroblasts suppressed TGF- $\beta 1$-induced FMT in a stepwise fashion, i.e., emergence of proto-myofibroblast, a-SMA stress fiber expression, and collagen production. It is particularly noteworthy that siRNA knockdown of LOXL2 almost completely suppressed the generation of differentiated myofibroblasts. Because TGF- $\beta 1$ is upregulated in BLM-induced fibrotic murine lungs [39], our data emphasize that LOXL2 expression is necessary for TGF- $\beta 1$-induced FMT during the pathological process of fibrotic lung scarring. Because the properties of myofibroblasts, that is, contractile force and excessive collagen production, contribute to the creation of the pathologic microenvironment of fibrotic disease, LOXL2 suppression represents a potentially highly efficient therapeutic strategy against fibrotic diseases.

LOXL2 participates in determination of cell fates, including those of hepatic progenitor cells [40], endothelial cells [32], and chondrocytes [41], as well as epithelial-mesenchymal transition (EMT) [31, 33] and the FMT, as shown here and in earlier studies [24, 34]. Several lines of research have elucidated the underlying molecular mechanisms by which nuclear LOXL2 contributes to cell fate decisions as an epigenetic regulator. During neural progenitor differentiation, LOXL2 oxidizes methylated TATA-binding protein-associated factor 10 (TAF10), a component of transcriptional factor IID (TFIID), and induces release of TAF10 from TFIID, leading to repression of TFIID-dependent genes and subsequent loss of pluripotency [30]. At the initial steps of EMT, LOXL2 is required for Snail-induced repression of noncoding pericentromeric RNA transcription (i.e., major satellites) through histone H3K4 oxidative deamination, which in turn induces transient release of heterochromatin $1 \mathrm{a}$ from heterochromatin foci and the subsequent heterochromatin reorganization necessary for completing the EMT [31]. In addition to the EMT, Snail is also essential for the FMT; accordingly, Snail1 deletion in cardiac fibroblasts nearly abolishes myofibroblast differentiation following exposure to TGF- $\beta 1$ [42]. In this study, we observed strong nuclear expression of LOXL2 and Snail in myofibroblasts after lung injury. At the same time, we also found that LOXL2 knockdown blocked TGF- $\beta 1$-induced FMT in association with downregulation of Snail expression. Based on these findings, we consider that the intracellular function of LOXL2 (i.e., cooperation with Snail in transcriptional regulation) is more important than its extracellular function (i.e., augmentation of ECM stiffness and subsequent induction of myofibroblast differentiation mediated by mechanotransduction) for the FMT and subsequent progression of fibrotic scarring. Recent findings that cells stably expressing the intracellular form of non-glycosylated LOXL2 ( $75 \mathrm{kDa})$, which has high affinity for the nucleus, are more strongly associated with the EMT than cells stably expressing secreted form of N-glycosylated LOXL2 ( $100 \mathrm{kDa})$ [43], support our hypothesis. 
We demonstrated that LOXL2 silencing inhibited upregulation of pSmad2 and Snail in TGF- $\beta 1$-treated lung fibroblasts. Snail is a target gene of the TGF- $\beta 1 /$ Smad2 pathway [44], and LOXL2 upregulates TGF$\beta 1$ signaling through phosphatidylinositol 3-kinase/AKT/mammalian target of rapamycin complex 1 signaling [45]. In addition, intracellular LOXL2 could protect Snail from glycogen synthase kinase 3 $\beta$ catalyzed Snail phosphorylation and subsequent ubiquitinylation and proteasomal degradation mediated by oxidization of Lys 98 and/or Lys 137 in the SNAG domain of Snail [33]. We observed intense nuclear expression of LOXL2 and Snail in myofibroblasts during the fibrotic phase of BLM-induced lung injury. Thus, LOXL2 might upregulate functional transcription activity of Snail not only activation of TGF$\beta 1 /$ Smad pathway in cytoplasm but also prevention of nuclear export and stabilization of Snail in nuclei during the process of FMT.

Besides the efficiency of FMT, the size of the AMP population, which is a major contributor to pathologically deleterious myofibroblasts [13], may also influence the progression of ARDS pathogenesis. Interestingly, we found that LOXL2 knockdown in lung fibroblasts potently suppressed the expression level of Postn (periostin), an intrinsic signaling ligand preferentially expressed in AMPs [13]. In vivo, genetic ablation of periostin-positive cells decreases collagen production and scar formation after myocardial infarction [46]. Moreover, excisional wounds created in the skin of periostin-knockout mice result in a significant decrease in the number of myofibroblasts with reduced contractile ability [47]. Based on this study and previous work, we speculate that inhibition of intracellular LOXL2 activity could prevent fibrotic scarring via reduction of the AMP population, as well as by blocking FMT.

In BALF from patients with ARDS, we observed elevated expression of LOXL2 protein in both the proliferative and fibrotic phases in comparison with patients in the exudative phase of ARDS or control subjects. These findings suggest that LOXL2 plays crucial roles in the progression of fibrosis in patients with ARDS. The fact that higher baseline serum LOXL2 levels are associated with increased risk of IPF disease progression [25] supports our idea. In regard to the regulation of LOXL2 expression, previous work demonstrates that microRNA (miR)-26a directly downregulates LOXL2 gene expression [48]. Because miR-26a is downregulated in a rat model of ARDS [49], the upregulation mechanisms of LOXL2 in the lungs of ARDS patients may be caused by downregulation of miR26a, in addition to TGF- $\beta 1$ [24]. Importantly, our clinical observation that LOXL2 was upregulated in the fibrotic phase of ARDS suggests that LOXL2 inhibition could exert anti-fibrotic effect in patients with ARDS. Future work is needed to determine which form of LOXL2 increased (i.e., secreted or intracellular) in BALF from patients with ARDS, as well as to validate our observations in distinct ARDS cohorts.

\section{Conclusions}

Our data reveal that nuclear LOXL2 is upregulated in the lung fibroblasts and myofibroblasts specifically during the fibrotic phase, and is required for the generation of myofibroblasts and maintenance of myofibrogenic progenitors. In the lungs of ARDS patients, we observed increased expression of LOXL2 during the fibrotic phase. We hope that the insights gained from this study will facilitate the development of treatments for ARDS. 


\section{Abbreviations}

a-SMA: a-smooth muscle actin; AMP: Axin2 + myofibrogenic progenitor; ARDS: acute respiratory distress syndrome; BALF: bronchoalveolar lavage fluid; BLM: bleomycin; BSA: bovine serum antigen; DAD: diffuse alveolar damage; DAPI: 4',6-diamidino-2-phenylindole; DMSO: dimethyl sulfoxide; ECM: extracellular matrix; ELISA: enzyme-linked immunosorbent assay; EMT: epithelial-mesenchymal transition; FMT: fibroblast-to-myofibroblast transition; FSP: fibroblast surface protein; ICU: intensive care unit; IPF: idiopathic pulmonary fibrosis; LOX: Iysyl oxidase; LOXL2: lysyl oxidase-like 2; miR: microRNA; PBS-T: Triton X-100 in PBS; qRT-PCR: quantitative real-time PCR; SP-C: surfactant protein C; siRNA: small interfering RNA; TAF10: TATA-binding protein-associated factor 10; TFIID: transcriptional factor IID; TGF$\beta 1$ : transforming growth factor $\beta 1$

\section{Declarations}

\section{Acknowledgments}

The author thanks Sumie Tajiri, Itsuki Morinaga, and Eiko Kurata for technical support.

\section{Authors' contributions}

Conception and design, A. Matsuo and S.Y. Analysis and interpretation A. Matsuo, S.Y., H.T., and A. Miura. Acquisition of data, A. Matsuo and S. Y. Draft writing A. Matsuo and S.Y. Review and revisions, H.T., A. Miura, T. S., N. M., and M. N. All authors read and approved the final manuscript.

\section{Funding}

This work was supported by JSPS KAKENHI Grant Number 18K08179 and grants from the Takeda Science Foundation and The Shin-Nihon Foundation of Advanced Medical Treatment Research (to S.Y.).

\section{Availability of data and materials}

All data generated or analyzed during the study are available from the corresponding author on reasonable request.

\section{Ethics approval and consent to participate}

All animal experiments were performed in accordance with the Japanese Physiological Society's guidelines for animal care and were approved by the Ethics Committee on Animal Experimentation of the University of Miyazaki. Human study was authorized by the University of Miyazaki Research Ethics Committee (No. 0-0531).

\section{Consent for publication}

Informed consent was obtained in the form of opt-out on our hospital website. 


\section{Competing interests}

The authors declare that there were no conflicts of interest.

\section{References}

1. Bellani G, Laffey JG, Pham T, Fan E, Brochard L, Esteban A, Gattinoni L, van Haren F, Larsson A, McAuley DF, et al. Epidemiology, patterns of care, and mortality for patients with acute respiratory distress syndrome in intensive care units in 50 countries. JAMA. 2016;315:788-800.

2. Rubenfeld GD, Caldwell E, Peabody E, Weaver J, Martin DP, Neff M, Stern EJ, Hudson LD. Incidence and outcomes of acute lung injury. N Engl J Med. 2005;353:1685-93.

3. Matthay MA, Zemans RL, Zimmerman GA, Arabi YM, Beitler JR, Mercat A, Herridge M, Randolph AG, Calfee CS. Acute respiratory distress syndrome. Nat Rev Dis Primers. 2019;5:18.

4. Thompson BT, Chambers RC, Liu KD. Acute respiratory distress syndrome. N Engl J Med. 2017;377:562-72.

5. Martin C, Papazian L, Payan MJ, Saux P, Gouin F. Pulmonary fibrosis correlates with outcome in adult respiratory distress syndrome. A study in mechanically ventilated patients. Chest. 1995;107:196-200.

6. Ichikado K, Muranaka H, Gushima Y, Kotani T, Nader HM, Fujimoto K, Johkoh T, Iwamoto N, Kawamura K, Nagano J, et al. Fibroproliferative changes on high-resolution CT in the acute respiratory distress syndrome predict mortality and ventilator dependency: a prospective observational cohort study. BMJ Open. 2012;2:e000545.

7. King TE, Jr., Bradford WZ, Castro-Bernardini S, Fagan EA, Glaspole I, Glassberg MK, Gorina E, Hopkins $P M$, Kardatzke D, Lancaster $L$, et al. A phase 3 trial of pirfenidone in patients with idiopathic pulmonary fibrosis. N Engl J Med. 2014;370:2083-92.

8. Richeldi L, du Bois RM, Raghu G, Azuma A, Brown KK, Costabel U, Cottin V, Flaherty KR, Hansell DM, Inoue $\mathrm{Y}$, et al. Efficacy and safety of nintedanib in idiopathic pulmonary fibrosis. N Engl J Med. 2014:370:2071-82.

9. Rockey DC, Bell PD, Hill JA. Fibrosis-a common pathway to organ injury and failure. N Engl J Med. 2015;372:1138-49.

10. Burnham EL, Janssen WJ, Riches DW, Moss M, Downey GP. The fibroproliferative response in acute respiratory distress syndrome: mechanisms and clinical significance. Eur Respir J. 2014;43:276-85.

11. Wang R, Ramos C, Joshi I, Zagariya A, Pardo A, Selman M, Uhal BD. Human lung myofibroblastderived inducers of alveolar epithelial apoptosis identified as angiotensin peptides. Am J Physiol. 1999;277:L1158-64.

12. Xie T, Liang J, Liu N, Huan C, Zhang Y, Liu W, Kumar M, Xiao R, D'Armiento J, Metzger D, et al. Transcription factor TBX4 regulates myofibroblast accumulation and lung fibrosis. J Clin Invest. 2016;126:3063-79. 
13. Zepp JA, Zacharias WJ, Frank DB, Cavanaugh CA, Zhou S, Morley MP, Morrisey EE. Distinct mesenchymal lineages and niches promote epithelial self-renewal and myofibrogenesis in the lung. Cell. 2017;170:1134-48.e1110.

14. Skruber K, Read TA, Vitriol EA. Reconsidering an active role for G-actin in cytoskeletal regulation. J Cell Sci. 2018;131.

15. Tomasek JJ, Gabbiani G, Hinz B, Chaponnier C, Brown RA. Myofibroblasts and mechano-regulation of connective tissue remodelling. Nat Rev Mol Cell Biol. 2002;3:349-63.

16. El Agha E, Kramann R, Schneider RK, Li X, Seeger W, Humphreys BD, Bellusci S. Mesenchymal stem cells in fibrotic disease. Cell Stem Cell. 2017;21:166-77.

17. Parker MW, Rossi D, Peterson M, Smith K, Sikstrom K, White ES, Connett JE, Henke CA, Larsson O, Bitterman PB. Fibrotic extracellular matrix activates a profibrotic positive feedback loop. J Clin Invest. 2014;124:1622-35.

18. Finney J, Moon HJ, Ronnebaum T, Lantz M, Mure M. Human copper-dependent amine oxidases. Arch Biochem Biophys. 2014;546:19-32.

19. Yamauchi M, Sricholpech M. Lysine post-translational modifications of collagen. Essays Biochem. 2012;52:113-33.

20. Rowbottom MW, Bain G, Calderon I, Lasof T, Lonergan D, Lai A, Huang F, Darlington J, Prodanovich P, Santini AM, et al. Identification of 4-(aminomethyl)-6-(trifluoromethyl)-2-(phenoxy)pyridine derivatives as potent, selective, and orally efficacious inhibitors of the copper-dependent amine oxidase, lysyl oxidase-like 2 (LOXL2). J Med Chem. 2017;60:4403-23.

21. Barry-Hamilton V, Spangler R, Marshall D, McCauley S, Rodriguez HM, Oyasu M, Mikels A, Vaysberg M, Ghermazien H, Wai C, et al. Allosteric inhibition of lysyl oxidase-like-2 impedes the development of a pathologic microenvironment. Nat Med. 2010;16:1009-17.

22. Vadasz Z, Kessler O, Akiri G, Gengrinovitch S, Kagan HM, Baruch Y, Izhak OB, Neufeld G. Abnormal deposition of collagen around hepatocytes in Wilson's disease is associated with hepatocyte specific expression of lysyl oxidase and lysyl oxidase like protein-2. J Hepatol. 2005;43:499-507.

23. Xiao Q, Ge G. Lysyl oxidase, extracellular matrix remodeling and cancer metastasis. Cancer Microenviron. 2012;5:261-73.

24. Aumiller V, Strobel B, Romeike M, Schuler M, Stierstorfer BE, Kreuz S. Comparative analysis of lysyl oxidase (like) family members in pulmonary fibrosis. Sci Rep. 2017;7:149.

25. Chien JW, Richards TJ, Gibson KF, Zhang Y, Lindell KO, Shao L, Lyman SK, Adamkewicz JI, Smith V, Kaminski N, O'Riordan T. Serum lysyl oxidase-like 2 levels and idiopathic pulmonary fibrosis disease progression. Eur Respir J. 2014;43:1430-8.

26. Harrison SA, Abdelmalek MF, Caldwell S, Shiffman ML, Diehl AM, Ghalib R, Lawitz EJ, Rockey DC, Schall RA, Jia C, et al. Simtuzumab is ineffective for patients with bridging fibrosis or compensated cirrhosis caused by nonalcoholic steatohepatitis. Gastroenterology. 2018;155:1140-53.

27. Muir AJ, Levy C, Janssen HLA, Montano-Loza AJ, Shiffman ML, Caldwell S, Luketic V, Ding D, Jia C, McColgan BJ, et al. Simtuzumab for primary sclerosing cholangitis: phase 2 study results with 
insights on the natural history of the disease. Hepatology. 2019;69:684-98.

28. Raghu G, Brown KK, Collard HR, Cottin V, Gibson KF, Kaner RJ, Lederer DJ, Martinez FJ, Noble PW, Song JW, et al. Efficacy of simtuzumab versus placebo in patients with idiopathic pulmonary fibrosis: a randomised, double-blind, controlled, phase 2 trial. Lancet Respir Med. 2017;5:22-32.

29. Herranz N, Dave N, Millanes-Romero A, Pascual-Reguant L, Morey L, Diaz VM, Lorenz-Fonfria V, Gutierrez-Gallego R, Jeronimo C, Iturbide A, et al. Lysyl oxidase-like 2 (LOXL2) oxidizes trimethylated lysine 4 in histone H3. FEBS J. 2016;283:4263-73.

30. Iturbide A, Pascual-Reguant L, Fargas L, Cebria JP, Alsina B, Garcia de Herreros A, Peiro S. LOXL2 oxidizes methylated TAF10 and controls TFIID-dependent genes during neural progenitor differentiation. Mol Cell. 2015;58:755-66.

31. Millanes-Romero A, Herranz N, Perrera V, Iturbide A, Loubat-Casanovas J, Gil J, Jenuwein T, Garcia de Herreros A, Peiro S. Regulation of heterochromatin transcription by Snail1/LOXL2 during epithelial-tomesenchymal transition. Mol Cell. 2013;52:746-57.

32. Neumann P, Jae N, Knau A, Glaser SF, Fouani Y, Rossbach O, Kruger M, John D, Bindereif A, Grote P, et al. The IncRNA GATA6-AS epigenetically regulates endothelial gene expression via interaction with LOXL2. Nat Commun. 2018;9:237.

33. Peinado H, Del Carmen Iglesias-de la Cruz M, Olmeda D, Csiszar K, Fong KS, Vega S, Nieto MA, Cano A, Portillo F. A molecular role for lysyl oxidase-like 2 enzyme in snail regulation and tumor progression. EMBO J. 2005;24:3446-58.

34. Wen X, Liu Y, Bai Y, Li M, Fu Q, Zheng Y. LOXL2, a copper-dependent monoamine oxidase, activates lung fibroblasts through the TGF-beta/Smad pathway. Int J Mol Med. 2018;42:3530-41.

35. Matute-Bello G, Frevert CW, Martin TR. Animal models of acute lung injury. Am J Physiol Lung Cell Mol Physiol. 2008, 295:L379-399.

36. Katzenstein AL, Bloor CM, Leibow AA. Diffuse alveolar damage--the role of oxygen, shock, and related factors. A review. Am J Pathol. 1976;85:209-28.

37. Tomashefski JF, Jr.. Pulmonary pathology of acute respiratory distress syndrome. Clin Chest Med. 2000;21:435-66.

38. Wu H, Yu Y, Huang H, Hu Y, Fu S, Wang Z, Shi M, Zhao X, Yuan J, Li J, et al. Progressive pulmonary fibrosis is caused by elevated mechanical tension on alveolar stem cells. Cell. 2020;180:107121.e117.

39. Broekelmann TJ, Limper AH, Colby TV, McDonald JA. Transforming growth factor beta 1 is present at sites of extracellular matrix gene expression in human pulmonary fibrosis. Proc Natl Acad Sci U S A. 1991;88:6642-6.

40. Ikenaga N, Peng ZW, Vaid KA, Liu SB, Yoshida S, Sverdlov DY, Mikels-Vigdal A, Smith V, Schuppan D, Popov YV. Selective targeting of lysyl oxidase-like 2 (LOXL2) suppresses hepatic fibrosis progression and accelerates its reversal. Gut. 2017;66:1697-708.

41. Iftikhar M, Hurtado P, Bais MV, Wigner N, Stephens DN, Gerstenfeld LC, Trackman PC. Lysyl oxidaselike-2 (LOXL2) is a major isoform in chondrocytes and is critically required for differentiation. J Biol 
Chem. 2011;286:909-18.

42. Biswas H, Longmore GD. Action of SNAIL1 in cardiac myofibroblasts is important for cardiac fibrosis following hypoxic injury. PLoS One. 2016;11:e0162636.

43. Moon HJ, Finney J, Xu L, Moore D, Welch DR, Mure M. MCF-7 cells expressing nuclear associated lysyl oxidase-like 2 (LOXL2) exhibit an epithelial-to-mesenchymal transition (EMT) phenotype and are highly invasive in vitro. J Biol Chem. 2013;288:30000-8.

44. Xu J, Lamouille S, Derynck R. TGF-beta-induced epithelial to mesenchymal transition. Cell Res. 2009;19:156-72.

45. Yang J, Savvatis K, Kang JS, Fan P, Zhong H, Schwartz K, Barry V, Mikels-Vigdal A, Karpinski S, Kornyeyev D, et al. Targeting LOXL2 for cardiac interstitial fibrosis and heart failure treatment. Nat Commun. 2016;7:13710.

46. Kanisicak O, Khalil H, Ivey MJ, Karch J, Maliken BD, Correll RN, Brody MJ, SC JL, Aronow BJ, Tallquist MD, Molkentin JD. Genetic lineage tracing defines myofibroblast origin and function in the injured heart. Nat Commun. 2016;7:12260.

47. Elliott CG, Wang J, Guo X, Xu SW, Eastwood M, Guan J, Leask A, Conway SJ, Hamilton DW. Periostin modulates myofibroblast differentiation during full-thickness cutaneous wound repair. J Cell Sci. 2012;125:121-32.

48. Kato M, Kurozumi A, Goto Y, Matsushita R, Okato A, Nishikawa R, Fukumoto I, Koshizuka K, Ichikawa T, Seki N. Regulation of metastasis-promoting LOXL2 gene expression by antitumor microRNAs in prostate cancer. J Hum Genet. 2017;62:123-32.

49. Huang C, Xiao X, Chintagari NR, Breshears M, Wang Y, Liu L. MicroRNA and mRNA expression profiling in rat acute respiratory distress syndrome. BMC Med Genomics. 2014;7:46.

\section{Figures}



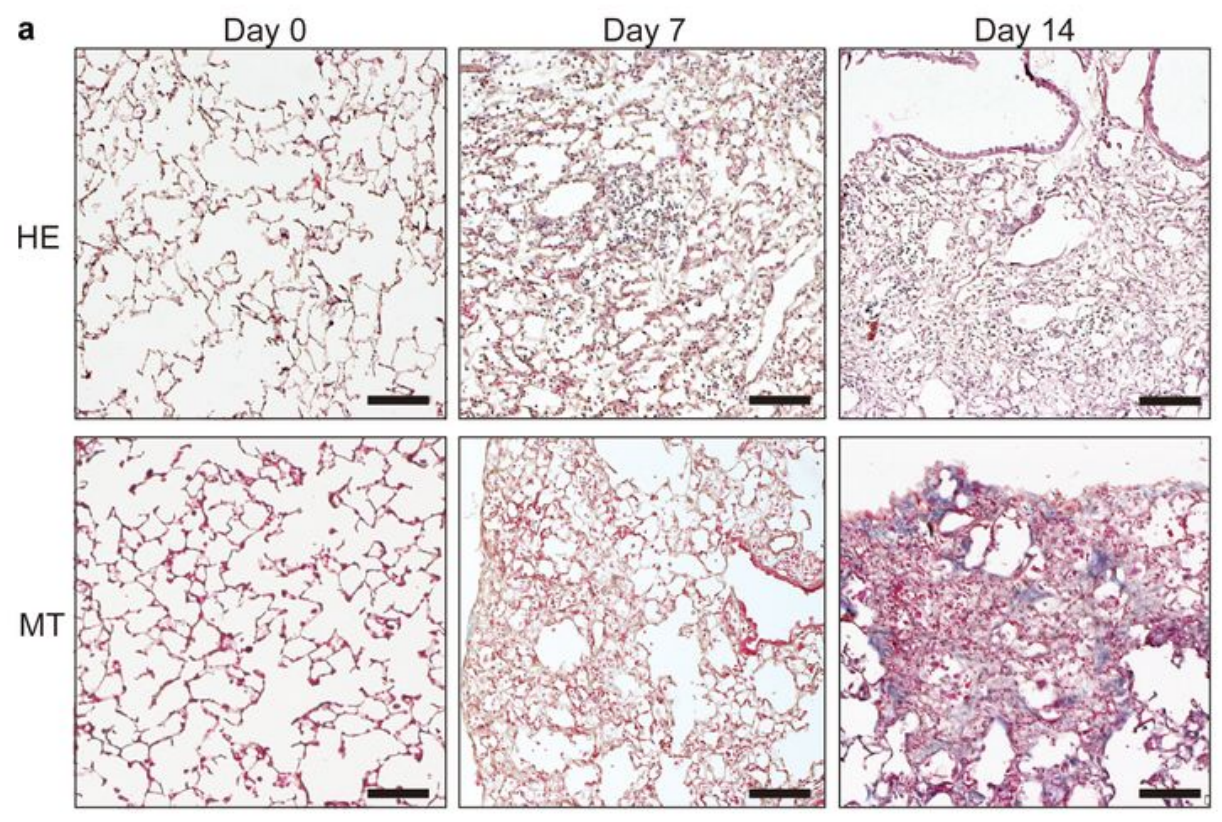

b
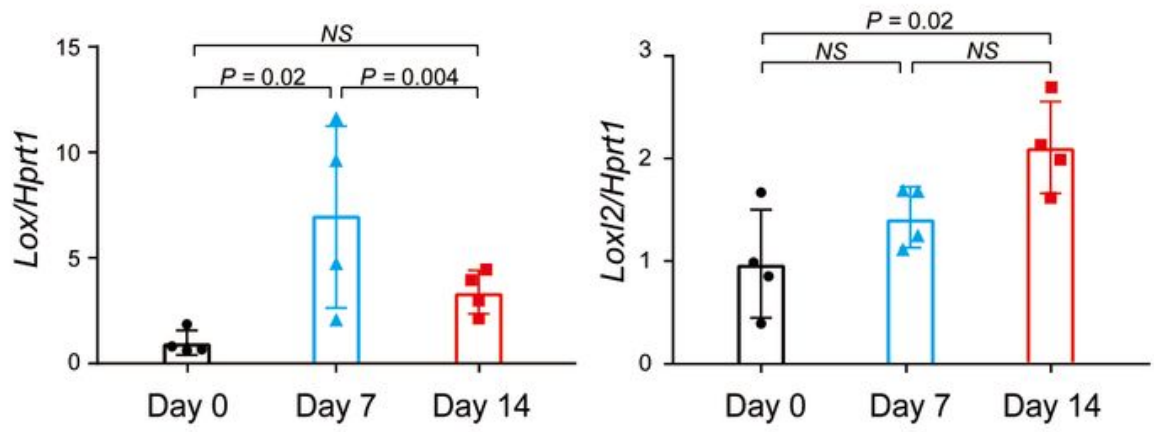

c
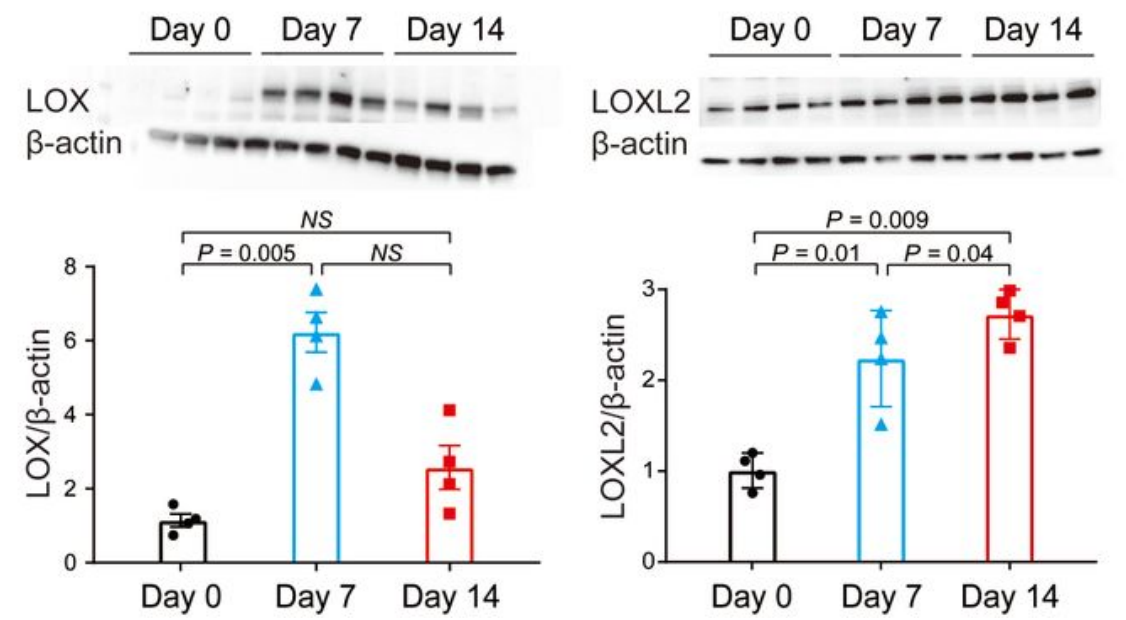

\section{Figure 1}

Increased expression of LOXL2 in the lungs during the fibrotic phase of BLM-induced lung injury. a Hematoxylin-eosin (HE) and Masson trichrome (MT) staining of lung sections of mice at baseline and 7 and 14 days after instillation of 6 units/kg of bleomycin (BLM). b mRNA levels of Lox and Loxl2 in whole lung lysates of mice at baseline and 7 and 14 days after instillation of 6 units $/ \mathrm{kg}$ of BLM. Gene expression was normalized against expression of the gene encoding hypoxanthine 
phosphoribosyltransferase 1 (Hprt1). c Representative immunoblots for LOX and LOXL2 protein in whole lung lysates at baseline and 7 and 14 days after instillation of 6 units $/ \mathrm{kg}$ of BLM. $\beta$-actin was used as a loading control. Sections are representative lung sections from four mice per group. Scale bar, $100 \mu \mathrm{m}$ (a). Data are expressed as means \pm SEM for $n=4$ mice per group (b, $c)$.

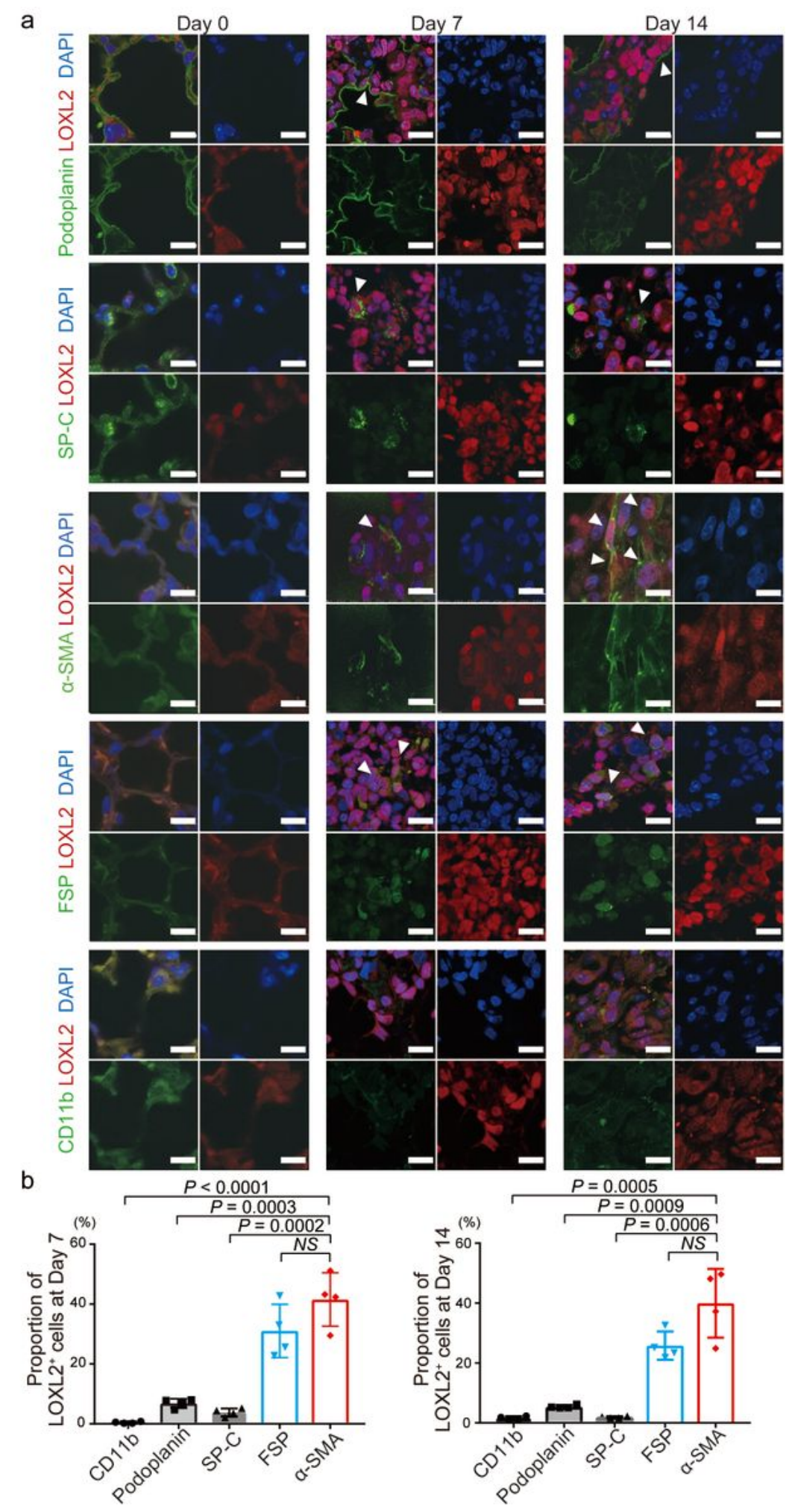

Figure 2 
Nuclear upregulation of LOXL2 in fibroblasts and myofibroblasts in the lungs of BLM-injected mice. a Double immunofluorescence staining of lung sections for LOXL2 (red), Podoplanin (alveolar type 1 cells, green), surfactant protein C (SP-C) (alveolar type 2 cells, green), a-smooth muscle actin (a-SMA) (myofibroblast, green), fibroblast surface protein (FSP) (fibroblast, green), and CD11b (macrophage, green) at baseline and 7 and 14 days after instillation of 6 units $/ \mathrm{kg}$ of bleomycin (BLM). DAPI was used to counterstain the nucleus (blue). Data are representative of four independent experiments per group. Scale bar, $10 \mu \mathrm{m}$. b Proportion of LOXL2-positive cells in each type of cells at 7 and 14 days after instillation of 6 units $/ \mathrm{kg}$ of BLM. Single (LOXL2)- or double (LOXL2 and each cell type-specific marker)positive cells in 10 random fields were counted. The proportion of LOXL2+ cells positive for each cell type-specific marker was calculated. Data are expressed as means \pm SEM for $n=4$ mice per group.
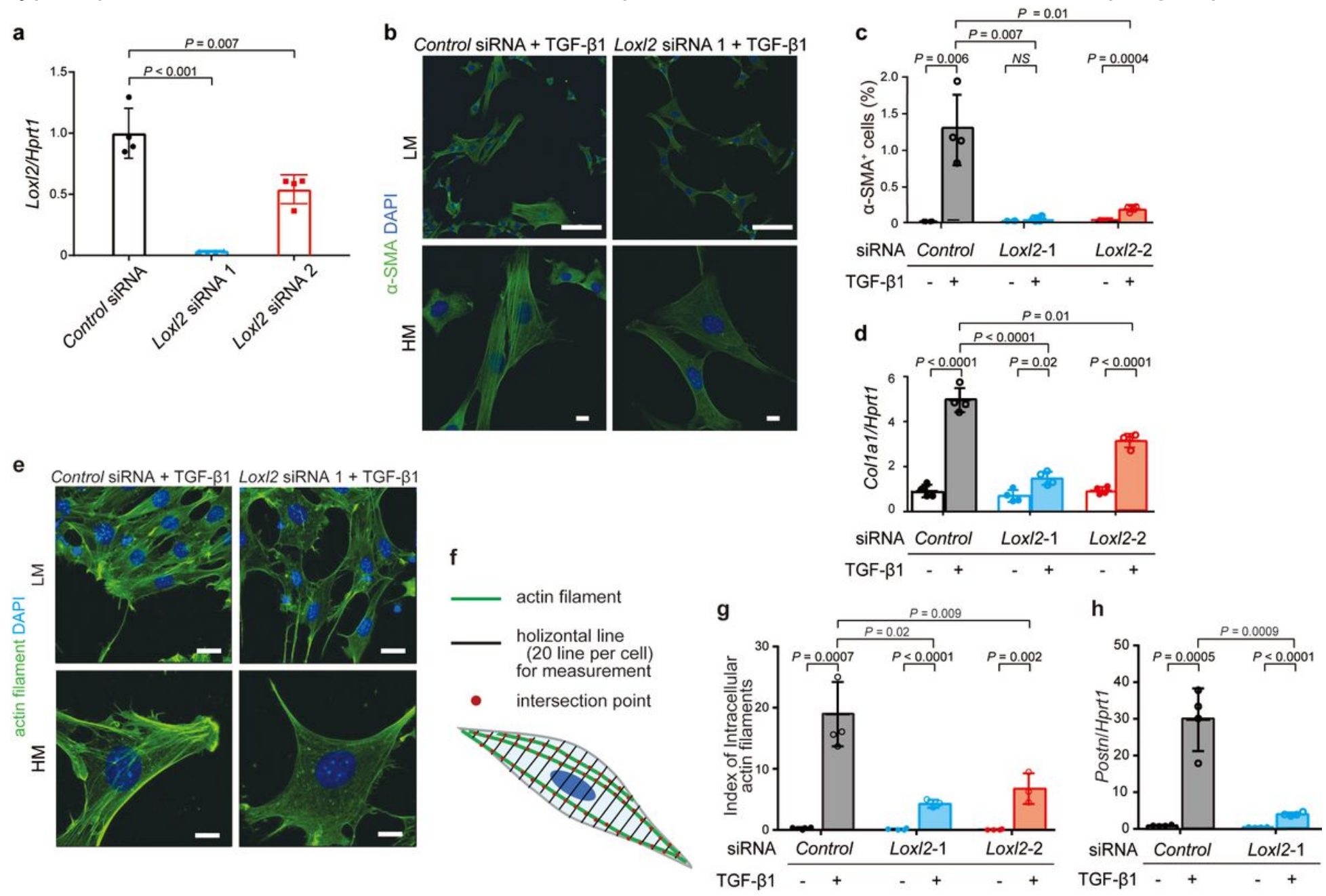

Figure 3 
LOXL2 knockdown suppresses TGF- $\beta 1$-induced myofibroblast generation in lung fibroblasts. a Loxl2 mRNA expression in transforming growth factor (TGF)- $\beta 1$-treated Mlg 2908 cells transfected with different siRNAs. b Immunofluorescence staining of control siRNA-(left panels) and Loxl2 siRNA1-(right panels) transfected, TGF- $\beta 1$-treated Mlg 2908 cells for $\alpha$-smooth muscle actin ( $\alpha$-SMA, green). DAPI was used to counterstain the nucleus (blue). Data are representative of four independent experiments per group. Scale bars: low magnification (LM), $100 \mu \mathrm{m}$; high magnification (HM), $10 \mu \mathrm{m}$. c Quantification of a-SMA stress fibers containing differentiated myofibroblasts treated with TGF- $\beta 1$ and transfected with different siRNAs. d Col1a1 mRNA expression in TGF- $\beta 1$-treated Mlg 2908 cells treated with the indicated siRNAs. e Actin filament staining with Alexa 488 phalloidin (green) of control siRNA-(left panels) and Loxl2 siRNA1-(right panels) transfected, TGF- $\beta 1$-treated Mlg 2908 cells. DAPI was used to counterstain the nucleus (blue). Data are representative of four independent experiments per group. Scale bars: LM, 50 $\mu \mathrm{m} ; \mathrm{HM}, 10 \mu \mathrm{m}$. $\mathrm{f}$ Schematic of quantification of intracellular actin filaments. Twenty equally distributed horizontal lines were overlaid on the immunostained images. For each line, intersection points with actin filaments were manually counted. g Quantification of intracellular actin filament in TGF- $\beta 1$-treated Mlg 2908 cells treated with the indicated siRNAs. h Postn mRNA expression in control siRNA- and Loxl2 siRNA 1-transfected, TGF- $\beta 1$-treated Mlg 2908 cells. Data and expressed as means \pm SEM for $n=4$ independent experiments (four wells per group) (a, c, d, g, and h). 
a
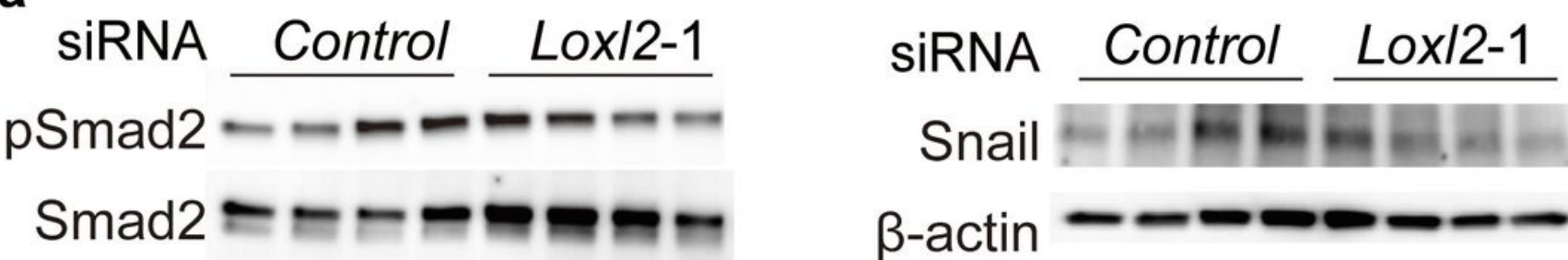

$\beta$-actin

b
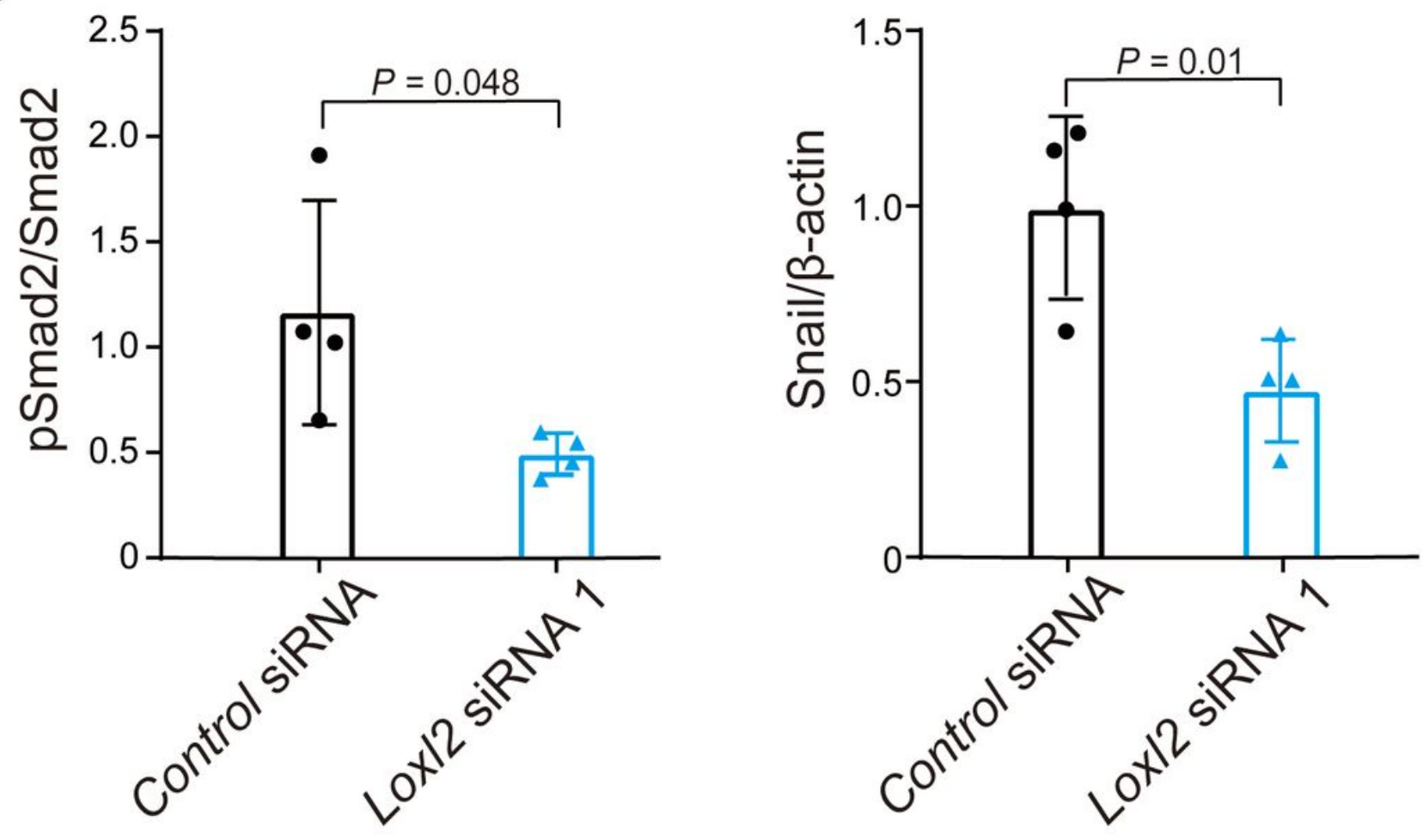

Figure 4

LOXL2 knockdown suppresses TGF- $\beta 1$-induced Smad2 phosphorylation and Snail expression in lung fibroblasts. $a, b$ Phosphorylated Smad2 and Snail expression were detected by immunoblotting of lysates of control siRNA- and Loxl2 siRNA 1-transfected, transforming growth factor (TGF)- $\beta 1$-treated Mlg 2908 cells. Quantitative comparisons were performed using total Smad2 and $\beta$-actin as loading controls. Data are expressed as means \pm SEM for $n=4$ independent experiments. 
a
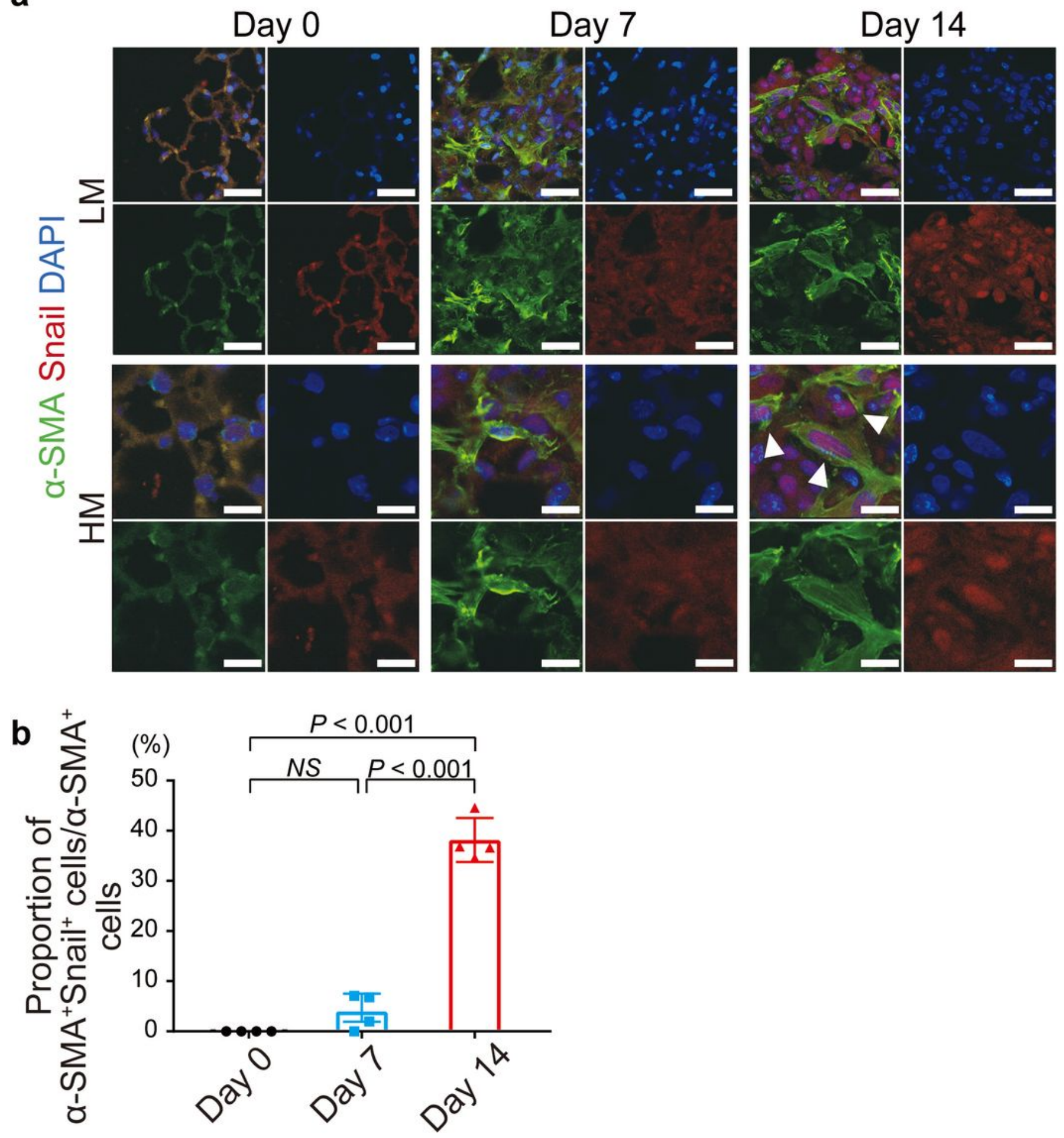

Figure 5

Increased nuclear expression of Snail in myofibroblasts during fibrotic stage of BLM-induced lung injury. a Double immunofluorescence staining for a-smooth muscle actin (a-SMA, green) and Snail (red) of lung sections at baseline and 7 and 14 days after instillation with 6 units $/ \mathrm{kg}$ of bleomycin (BLM). DAPI was used to counterstain the nucleus (blue). Data are representative of four independent experiments per group. Scale bar: low magnification (LM), $20 \mu \mathrm{m}$; high magnification (HM), $10 \mu \mathrm{m}$. b Quantification of a- 
SMA+Snail+ cells in lung sections at baseline and 7 and 14 days after instillation with 6 units $/ \mathrm{kg}$ of BLM. Data are means \pm SEM of $n=4$ mice per group.

a
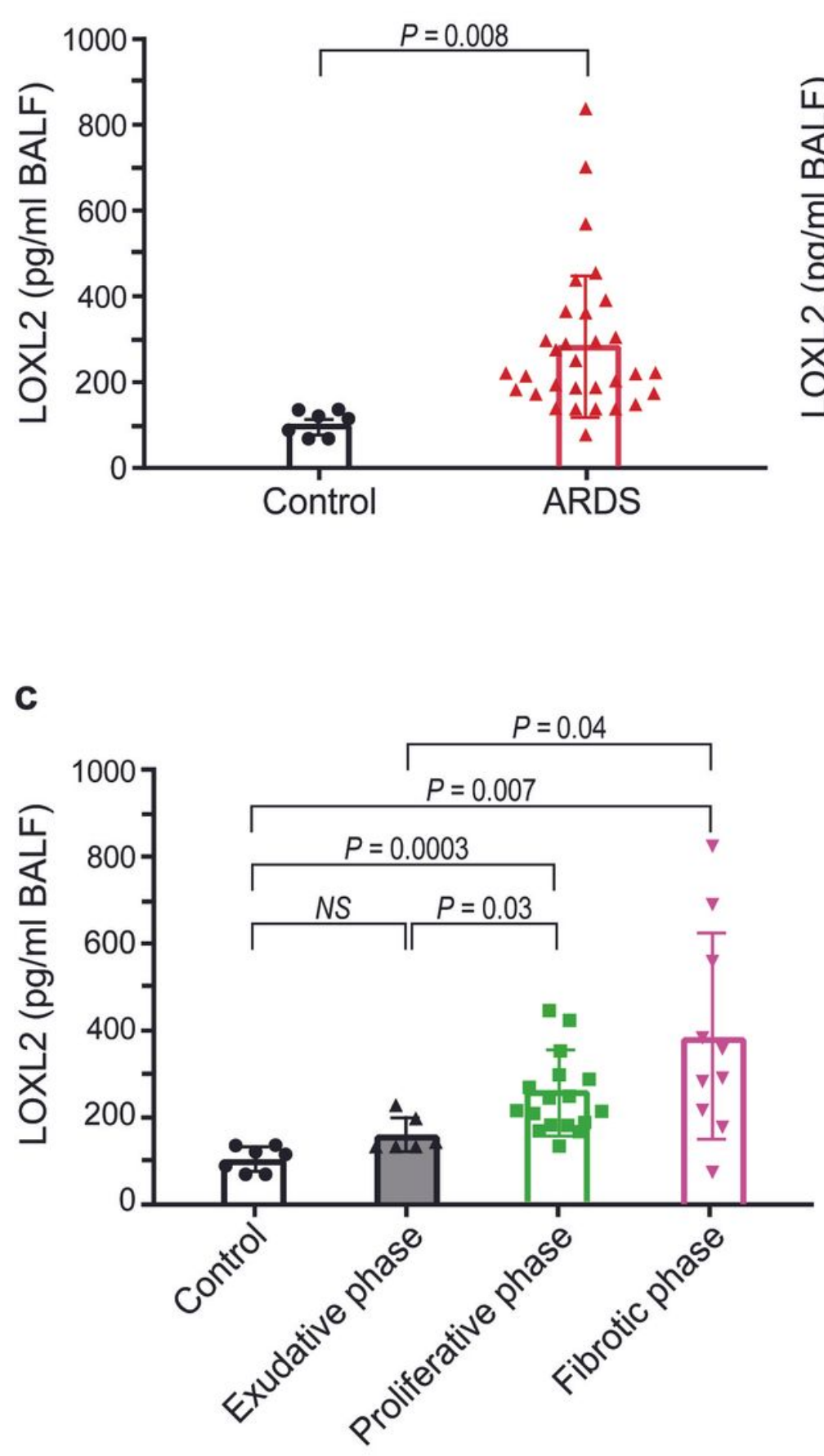

b

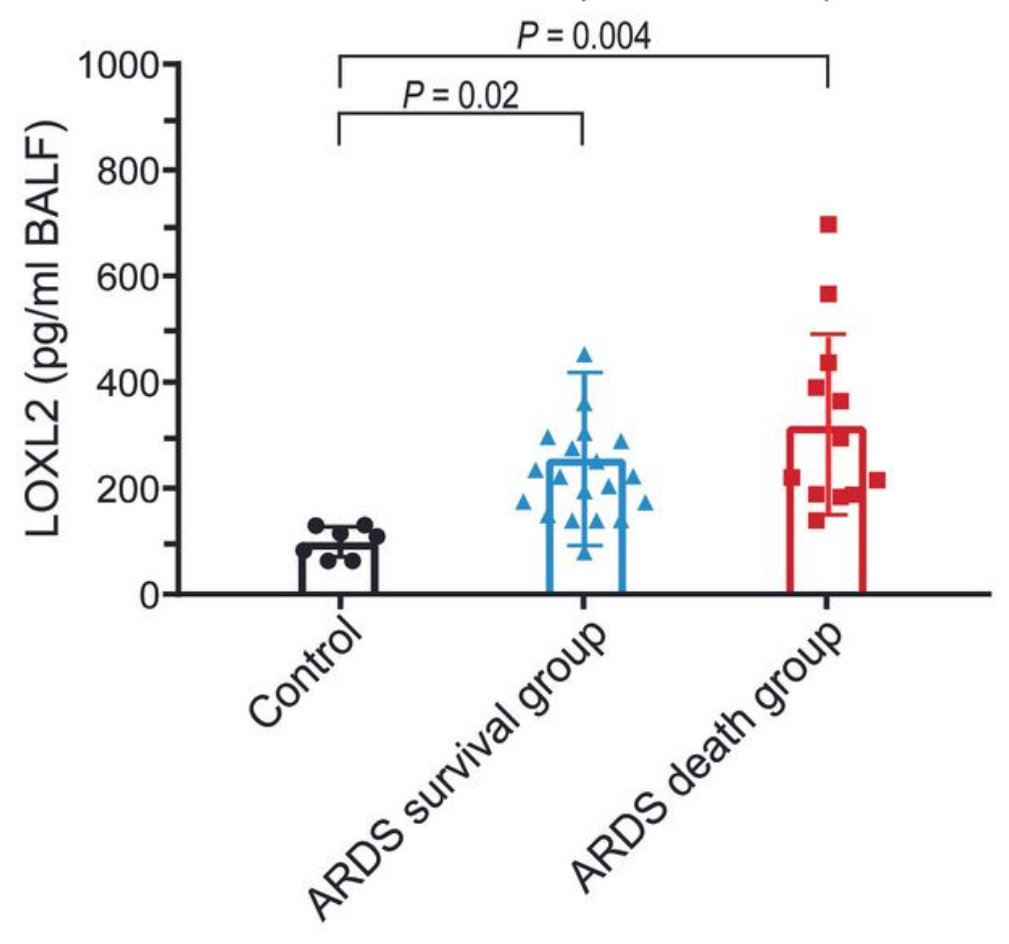

Figure 6

High levels of LOXL2 in the BALF in patients with ARDS during the fibrotic phase. a LOXL2 concentrations in bronchoalveolar lavage fluid (BALF) from control subjects and patients with acute respiratory distress syndrome (ARDS). b LOXL2 concentrations in BALF from control subjects, surviving patients with ARDS, and patients who died of ARDS. c LOXL2 concentrations in BALF from control subjects, patients with ARDS who underwent bronchoalveolar lavage in the exudative phase (from onset to day 3 ), those in 
proliferative phase (from day 4 to day 9), and those in fibrotic phase (day 10 and beyond). Data are means \pm SEM for 33 patients with ARDS and 7 control subjects (a), 20 survived patients with ARDS, 13 patients who died of ARDS, and 7 control subjects (b), 6 patients with ARDS in exudative phase, 17 patients with ARDS in proliferative phase, 10 patients with ARDS in fibrotic phase, and 7 control subjects (c). 